\title{
STABILITY ANALYSIS OF RAILWAY SUBGRADE IN MINING AREA BASED ON DINSAR
}

\author{
Jun $\mathrm{Xu}^{1}$, Jinshan $\mathrm{Hu}^{1}$, Jin Ding ${ }^{1}$ \\ ${ }^{1}$ School of Geography, Geomatics and Planning, Jiangsu Normal University \\ 101 Shanghai Road, Xuzhou, Jiangsu, China, 221116 \\ XZjshu@163.com
}

Commission III, WG III/3

KEY WORDS: Stability analysis, Mining subsidence, Railway subgrade, DInSAR, Sentinel-1A data

\begin{abstract}
:
DInSAR technology have been applied to monitor the mining subsidence and the stability of the railway subgrade. A total of 10 Sentinel-1A images acquired from 2015/9/26 to 2016/2/23 were used in DInSAR analysis. The study mining area is about $13.4 \mathrm{~km}^{2}$. Mining have induced serious land subsidence involve a large area that causing different levels of damages to infrastructures on the land. There is an important railway near the mining area, the DInSAR technology is applied to analyse the subsidence near the railway, which can warn early the possible deformation that may occur during underground mining. The DInSAR results was verified by the field measurement. The results show that the mining did not cause subsidence of railway subgrade and did not affect the stability of railway subgrade.
\end{abstract}

\section{INTRODUCTION}

Mining have induced serious land subsidence involve a large area that causing different levels of damages to infrastructures on the land(Shaochun,2013a;Yu,2007a;Zhou,2016a). At the same time, with the rapid development of economic takes much pressure on transportation that accelerate the construction of the railway(Qingli,2017a). The intensity of the railway system is becoming much more considerable. Coal mining may affect the safety of railway with different ways and different levels(Meinan,2017a). The analysis of the stability of railway subgrade in mining area is of great importance that relevant with the safety of the railway directly. The common methods for railway deformation monitoring are settlement plates, observation pile and sensor monitoring. The traditional monitoring methods are vulnerable to the impact of rolling and collision of construction machinery and are easy to be damaged, so that induce errors in the monitoring results (Galve,2015a;Ng,2017a;Poreh,2017a;Qingli,2017a).

Differential Interferometric Synthetic Aperture Radar(DInSAR) is an advanced remote sensing technology, which has been widely applied in surface subsidence monitoring for its all-time, all-weather and wide area monitoring ability, instead of traditional leveling and GPS(Castañeda,2009a;Shaochun, 2013a). Compared with the traditional monitoring method, DInSAR technology can monitor a larger scale and denser surface subsidence(Qingli,2017a)and acquire the surface subsidence values of the whole mining area without construction of deformation monitoring network. These characteristics of DInSAR technology are very significant for subsidence monitoring in mining area(Strozzi,2001a;Perski,1999a).

One of the hindrance of SAR data has been the high price. It's costly for the subsidence observation of some areas but with serious subsidence, such as many coal mine in China. China is a big coal producer, in some province of China(such as Shanxi, Shandong, etc.) operate many coal mine, the effect of land subsidence caused by coal mining has caused lots of disasters. In order to prevent the disasters, monitoring of the subsidence in mining area has been one of the most importing thing in coal mining. With the launch of Sentinel satellite, the cost of SAR data decreased dramatically. Sentinel-1A C-band data has the short revisit time of 12 days as compared to the 35 days of ERS and ENVISAT. Sentinel data is economical for subsidence detection of some areas. This paper aim to explored the possibility of Sentinel-1A data to monitoring the subsidence.

In this paper, the main aim of our work was to exploit the potential of Sentinel-1A data for railway subsidence monitoring and more detail information are expected to be detected by Cband data. Deformation of the railway in the mining area was monitored by DInSAR based on a total of 10 Sentinel-1A images(Qihuan,2017a). An estimate of the precision of the monitoring of subsidence with Sentinel-1A data is analysed and validation of the leveling data around the railway and the working face is made.

\section{STUDY AREA, SENTINEL-1A DATA AND LEVELING DATA}

The study area is located to the southwest of Changzhi downtown in Shanxi Province of China, as illustrated in Figure 1. Coal mining is one of the major economic developments in Changzhi downtown, but coal mining will also cause land subsidence. Subsidence is one of the most important geological disasters in Changzhi. Subsidence seriously affects construction and maintain of infrastructures so that prevent urban from rapid development.

In the study area, the underground coal seam and its surrounding rocks are a syncline structure, and there are 8 faults near the coal seam. Figure 1 shows the location of the study area. The red rectangle is the working face and the black points are leveling points. The leveling points are distributed on five observation lines, the five observation lines of longitudinal line $\mathrm{A} 1, \mathrm{~A} 2, \mathrm{~A} 3$ and transverse observation line $\mathrm{B} 1, \mathrm{~B} 2$ are illustrated 
in Figure 1. There is a railway and Nanzhang village over the north of the working face. The topography near the railway subgrade is relatively flat. The length of the working face is $943 \mathrm{~m}$ and its width is $159 \mathrm{~m}$, the average mining depth of the working face is $408 \mathrm{~m}$, the average coal thickness is $5.6 \mathrm{~m}$ and the angle of coal seam is $9^{\circ}$. Mechanized sublevel caving method is applied to exploit the underground coal. A railway is important for passenger and freight transport, which is crossing near the working face. This paper aims to studying if the mining activities will induce the railway subgrade subsidence. The DInSAR technology is applied to analyze the subsidence near the railway, which can warn early the possible deformation that may occur during underground mining.

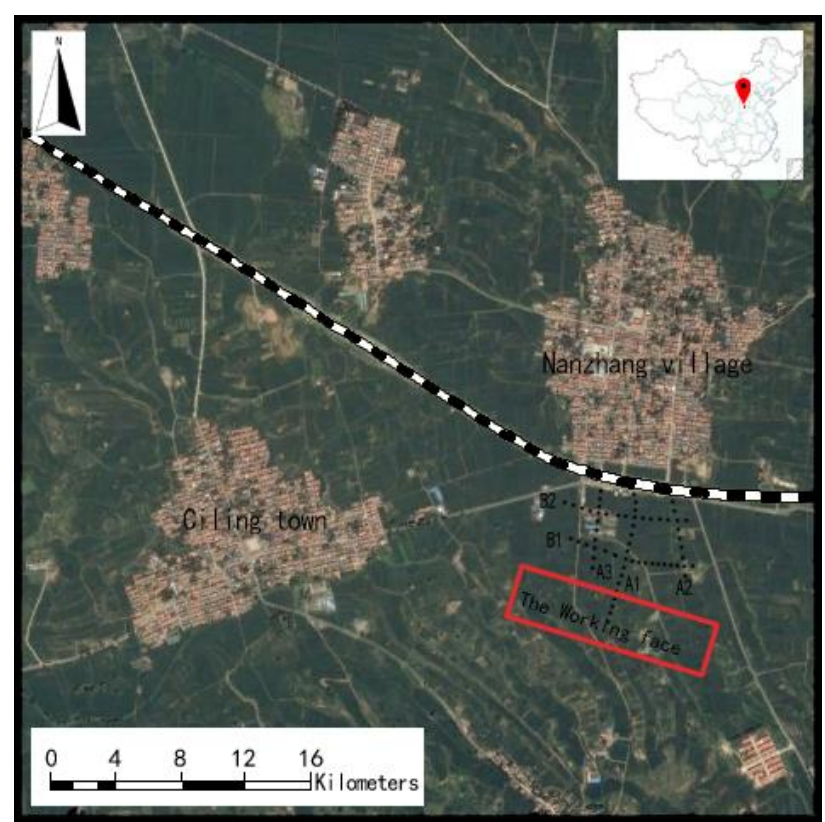

Figure 1. Location of the study area from google earth

In this paper, a total of 10 Sentinel-1A images acquired from $2015 / 9 / 26$ to $2016 / 5 / 23$ are used for analysis. The polarization is VV. The incidence angle is $41.6^{\circ}$. The center latitude and longitude of the image is $36.05^{\circ}$ and $112.95^{\circ}$ respectively. The spatial baseline and temporal baseline is an important factor in choosing a suitable data pair. For these Sentinel-1A data, the largest perpendicular baseline is approximately $107 \mathrm{~m}$, which can avoid spatial decorrelation, the largest temporal baseline is 48 days which relatively prevent the decrease of the coherence of interferograms. Table 1 explains the acquisition data and baseline of the related images.

\begin{tabular}{cccc}
\hline Scenes & Date $(\mathrm{yy} / \mathrm{mm} / \mathrm{dd})$ & Interval(days) & Baseline $(\mathrm{m})$ \\
\hline 1 & 20150926 & 0 & 0 \\
2 & 20151020 & 24 & -74.511 \\
3 & 20151113 & 24 & 106.909 \\
4 & 20151207 & 24 & -55.048 \\
5 & 20151231 & 24 & -38.307 \\
6 & 20160217 & 48 & 29.826 \\
7 & 20160312 & 24 & -8.009 \\
8 & 20160405 & 24 & -15.468 \\
9 & 20160429 & 24 & -22.973 \\
10 & 20160523 & 24 & 74.875 \\
\hline
\end{tabular}

Table 2. Sentinel-1A data and description
The leveling data were acquired with an approximately frequency of once per month from July 2015 to March 2017, except for no available data in some months. A total of 15 observations were conducted, the detail information of the leveling data is illustrated in Table 2. The initial subsidence was assumed to be zero, starting from 8 July 2015 and the accumulated subsidence can be calculated based on this leveling data. Figure 1 shows the position of the five leveling lines between the working face and the railway. The total of 61 leveling points numbered with ID 1 to 61 are distribute on five lines of $\mathrm{A} 1, \mathrm{~A} 2, \mathrm{~A} 3, \mathrm{~B} 1$ and $\mathrm{B} 2$.

\begin{tabular}{cccc}
\hline No. & Acquisition Time & No. & Acquisition Time \\
\hline 1 & 20150708 & 9 & 20160424 \\
2 & 20150730 & 10 & 20160523 \\
3 & 20150901 & 11 & 20160626 \\
4 & 20151004 & 12 & 20160804 \\
5 & 20151104 & 13 & 20161006 \\
6 & 20160103 & 14 & 20161129 \\
7 & 20160204 & 15 & 20170304 \\
8 & 20160320 & & \\
\hline
\end{tabular}

Table 3. Leveling data acquisitions

\section{DINSAR ANALYSIS}

\subsection{DEM co-registration}

External DEM was applied for topographic effect removal. The baselines of the data higher tan $50 \mathrm{~m}$ usually need topographic effect removal. The topographic effect removal is based on the co-registration of a differential interferograms with a DEM and a subsequent extraction of the topographic effects(Zbigniew,1998). The precision of DEM co-registration will affect the result of the topographic effects. In this paper, DEM is selected from the Shuttle Radar Topography Mission(SRTM), with 3 arc-sec resolutions, which was applied for topographic effect removal. In this case, the largest baseline is approximately $107 \mathrm{~m}$ and others are less than $100 \mathrm{~m}$ all. So, the topographic effects can be easily removed.

\subsection{DInSAR analysis}

DInSAR analysis is applied to monitor the sequential subsidence of the study area. The two-pass DInSAR method is adopted to process the 10 Sentinel-1A data, the DEM is selected from SRTM with 3 arc-sec resolutions. Selecting the Sentinel data acquired at September $26^{\text {th }}, 2015$ as the master image. Then generating 9 interferograms based on 10 available InSAR images. In order to remove the influence of noise and improve the precision of phase unwrapping, adaptive filtering is adopted to improve the quality of interference fringes. Combined with GPS data, the accumulating DInSAR results of sequential subsidence are acquired. As the $10 \mathrm{~m}$ external DEM error will only lead to about $0.9 \mathrm{~mm}$ error of the accumulating deformation, so the external DEM error can be ignored. The final results of the accumulating subsidence of DInSAR results are shown in Figure 2. The black line represent the railway, the blue rectangle area is the working face and the red dots is the leveling points distributed between the working face and the railway. The growing red area is the subsidence area monitored by DInSAR. 

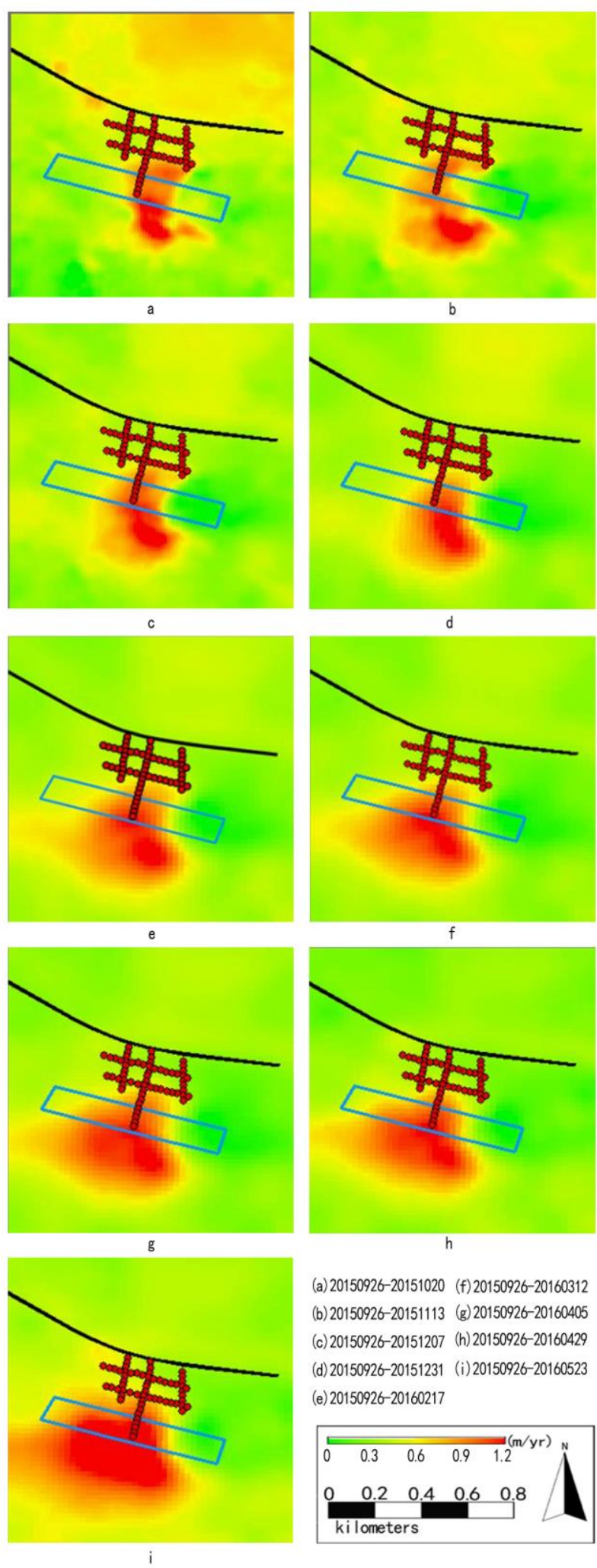

(a) 20150926-20151020 (f) 20150926-20160312 (b) 20150926-20151113 (g) 20150926-20160405 (c) 20150926-20151207 (h) 20150926-20160429 (d) 20150926-20151231 (i) 20150926-20160523 (e) 20150926-20160217

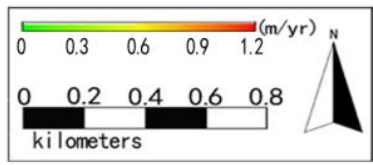

Figure 4. The accumulating subsidence DInSAR results

The accumulating sequential subsidence results in Figure 2 shows that with the working face advance, the range of the subsidence area increased obviously. The results show that as the working face advance, the subsidence area extends along the south of the working face, the north of the working face is almost unaffected by the land subsidence. The railway in this study is in the north of the working face. So the InSAR results shows that the subsidence induce by coal mining will not affect the safety of the railway.

\section{VALIDATION WITH LEVELING DATA}

The leveling data was surveyed with an approximately frequency of once per month from July 2015 to March 2017. The total 15 observations acquired the subsidence values of each observation and accumulate observation. The DInSAR results was extracted coincidence with the leveling points. The comparison between leveling data and DInSAR data is illustrated in Figure 3. The hexagonal points represent the leveling data, the triangular points represent the DInSAR data and the red rectangle is the differences between the leveling data and the DInSAR data.

In Figure 3, there are 67 leveling points validate with DInSAR data, because when surveying in the field, there are 6 points of repeated observation. They are point 4 and 8 in line A1, point 21 and 25 in A2, point 30 and 34 in line A3. These points were repeat observed when the observation of line B1 and B2. When extract the DInSAR data, also extract second time of the repeat observed points.

Figure 3 shows that the leveling data and DInSAR match very well. The maximum error occurs at point 10 in line A1 and point 36 in line A3, the difference is about 1.8 centimeters. The validation results show that DInSAR technology has high precision when monitor the subsidence.
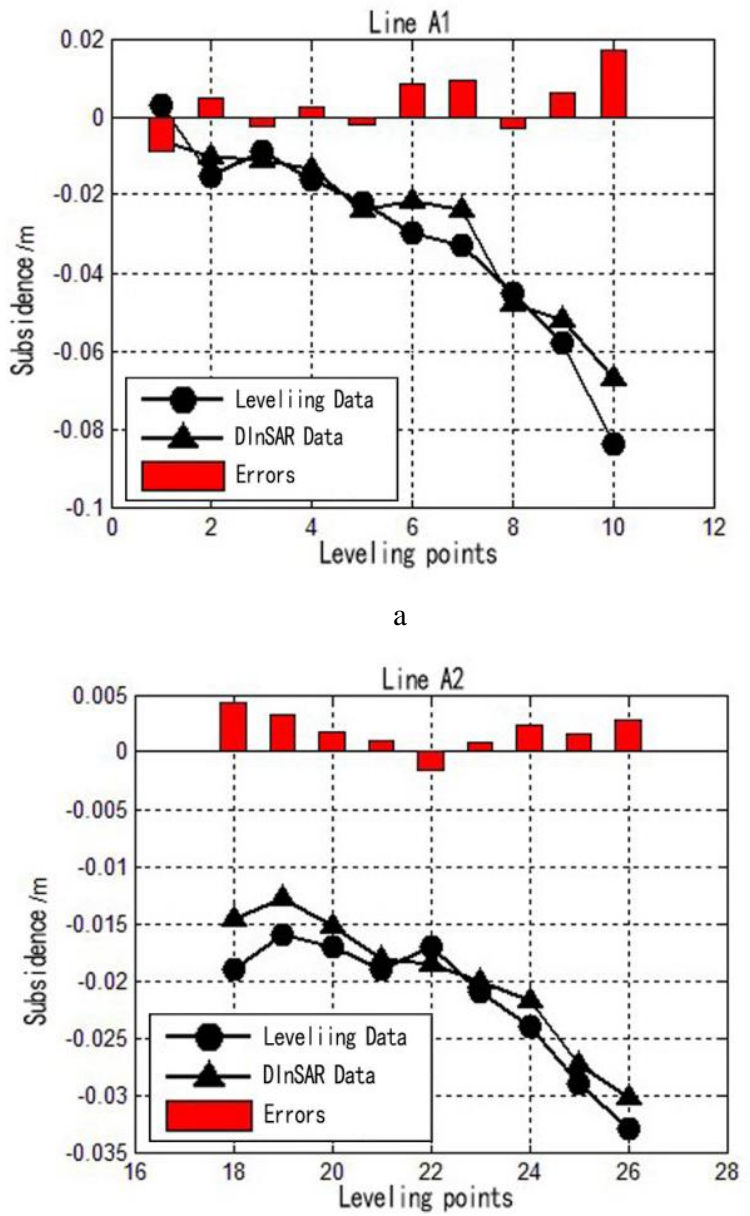

b 


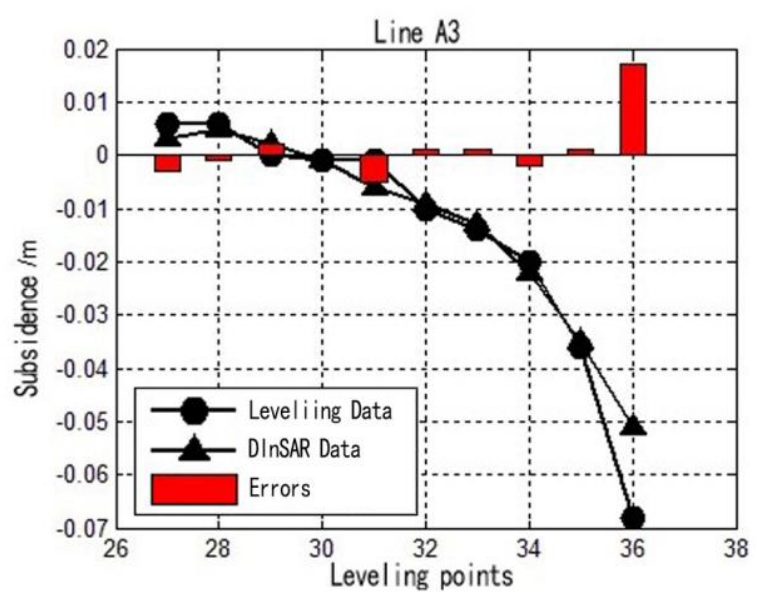

$\mathrm{c}$

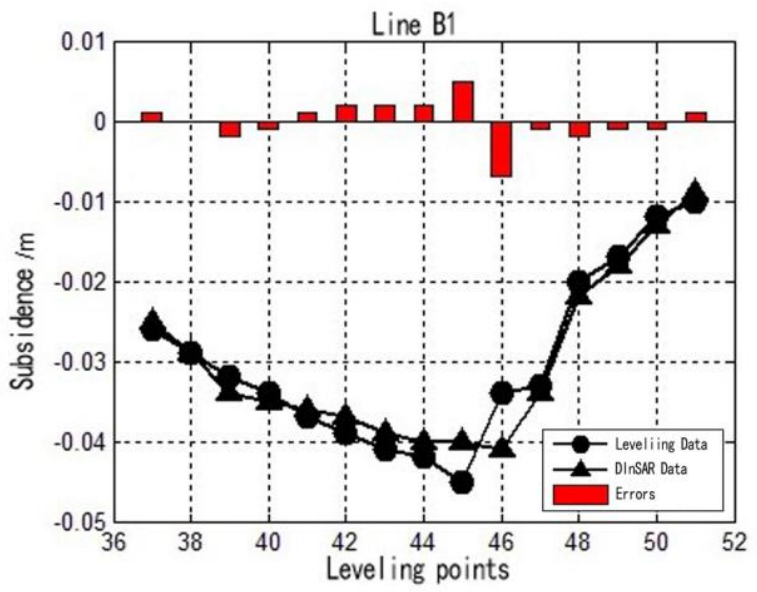

d

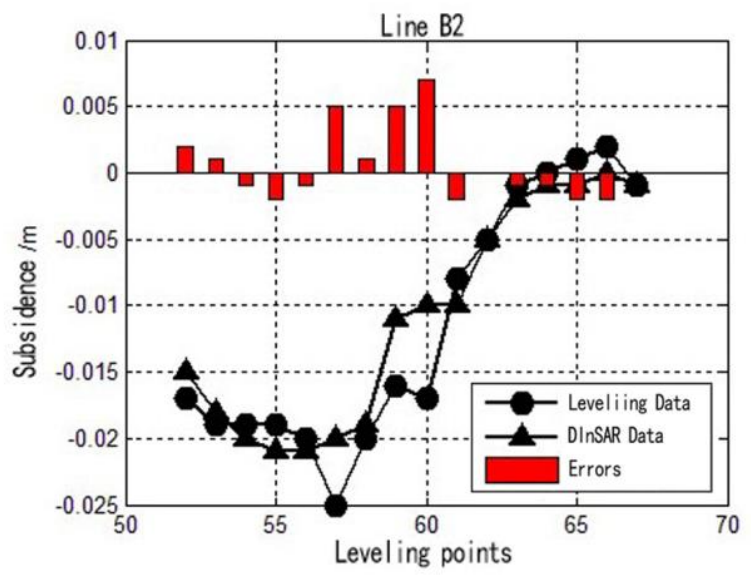

Figure 5. Comparison between leveling data and DInSAR data

\section{DISCUSSION AND CONCLUSION}

The launch of Sentinel satellite offering free SAR images, Sentinel-1A data have improved the capability of monitoring subsidence in some small coal mine with lower cost. And the shorter revisiting cycle of Sentinel data can ensure the accuracy of the subsidence monitoring. China is the largest coal producer in the world and Shanxi province is largest coal producer in
China. There are many coal mines in China's coal producing province, especially in Shanxi province. The study area is located in Changzhi downtown, Shanxi province. Consecutive coal mining will induce different degree of geological hazards, including mining landslides, land subsidence and so on. It will have a serious impact on the local ecological environment and the safety of people's lives and property. In order to prevent the potential disaster in mining area, subsidence monitoring is essential in coal mining area. DInSAR technology has been widely applied for monitoring land subsidence caused by coal mining. In this study, DInSAR process results validate by leveling data, shows the veracity of DInSAR technology monitoring in coal mining area. Sentinel-1A data is using in the study, compare with other SAR data, sentinel-1A data have shorter revisit cycle of 12 days, and sentinel-1A data is free to access, this dramatically reduce the cost for subsidence monitoring. So that many small coal mine can use sentinel-1A data to monitor the subsidence in the mining area to prevent the potential disaster with low cost. In this study area, there's an important railway cross the mining area, the safety of railway subgrade around the mining area will affect the operate of the railway. The stability of the railway subgrade is greatly affected by the land subsidence. The monitoring results provided guidance for the prevention of railway subgrade safety problems.

The above presented results demonstrate that the subsidence of the railway near the coal mining working face could be investigated by Sentinel-1A data and DInSAR technology can monitor the subsidence accurately. The comparison results for average subsidence velocity and displacement show that DInSAR results can provide a precise subsidence information, with high temporal and spatial sampling, and could achieve a millimetre level of accuracy. Compared with leveling data, DInSAR has the ability for wide coverage, high precision, and fast monitoring.

Traditional leveling data are able to provide reliable observation of surface subsidence. However, they are limited by low spatial sampling density and high cost. In this paper, the monitoring of the working face and railway in mining area is carried out by 10 Sentinel-1A data. The results demonstrated that Sentinel-1A data has potential ability to monitor the mining subsidence and the stability of the railway subgrade. The results of data analysis show that the mining in the working face did not cause subsidence of railway subgrade and did not affect the stability of railway subgrade, which ensure the safety of railway near the working face.

\section{ACKNOWLEDGEMENTS}

The work described in this paper is supported by the National Nature Science Foundation of China under grant No.41671395 and No.51574132.

\section{REFERENCES}

Alex Hay-Man N., Linlin G., Zheyuan D., Shuren W., and Chao M., 2017a. Satellite radar interferometry for monitoring subsidence induced by longwall mining activity using Radarsat2, Sentinel-1 and ALOS-2 data. International Journal of Applied Earth Observation and Geoinformation,61,pp.91-103.

Carmen C., Francisco G., Michele M., and Jorge P. G., 2009a. DInSAR measurements of ground deformation by sinkholes, 
mining subsidence, and landslides, Ebro River, Spain. Earth Surface Processes and Landforms,34(11),pp.1562-1574.

Davod P., Antonio I., Daniele R., and Giuseppe R., 2016a. Railways' stability observed in Campania (Italy) by InSAR data. European Journal of Remote Sensing,49(1),pp.417-431.

Galve J.P., Castañeda C., and Gutiérrez F., 2015a. Railway deformation detected by DInSAR over active sinkholes in the Ebro Valley evaporite karst, Spain. Natural Hazards and Earth System Science, 15(11),pp.2439-2448.

Meinan Z., Yixuan L., Kazhong D., Chenliang Z., and Jun F., 2017a. Monitoring and Prediction of Railway Deformation based on DInSAR and Probability Integral Method. Bulletin of Surveying and Mapping,2017(1),pp.106-111.

Perski Z., and Jura D., 1999a. ERS SAR interferometry for land subsidence detection in coal mining areas. Earth Observation Quarterly.63,pp.25-29.

Qihuan H., Michele C., Oriol M., and Bruno C., 2017a. Displacement monitoring and modelling of a high-speed railway bridge using C-band Sentinel-1 data. ISPRS Journal of Photogrammetry and Remote Sensing,128,pp.204-211.

Qingli L., Guoqing Z., and Daniele P., 2017a. Monitoring of Subsidence along Jingjin Inter-City Railway with HighResolution TerraSAR-X MT-InSAR Analysis. Remote Sensing,9(7),pp.717-731.

Shaochun D., Hongwei Y., Suping Y., and Fei Z., 2013a. Detecting surface subsidence in coal mining area based on DInSAR technique. Journal of Earth Science,24(3),pp.449-456.

Strozzi T., Wegmüller U., Tosi L., Bitelli G., and Spreckels V., 2001a. Land subsidence monitoring with differential SAR interferometry. Photogrammetric Engineering and Remote Sensing.67(11),pp.1261-1270.

Yu Q., Wang W., and Yi C., 2007a. Design and Application of an Automatic System for Land-subsidence and Water Table Monitoring in Tianjin City. Ground Water,29(5),pp.101-104.

Zhou G., Yan H., Chen K., and Zhang R., 2016a. Spatial analysis for susceptibility of second-time karst sinkholes: A case study of Jili Village in Guangxi, China. Comput. Geosci,89.pp.144-160.

Zbigniew Perski., 1998. Applicability of ERS-1 and ERS-2 InSAR for land subsidence monitoring in the silesian coal mining region, Poland. In: International Archives of Photogrammetry and Remote Sensing, Vol. XXXII, Part 7, pp.555-558. 